\title{
Describing the diurnal relationships between objectively measured mother and infant physical activity
}

\author{
Alessandra Prioreschi ${ }^{*^{*}} \mathbb{D}$, Soren Brage ${ }^{2}$, Kate Westgate $^{2}$ and Lisa K. Micklesfield ${ }^{1}$
}

\begin{abstract}
Background: Evidence for the importance of accumulating sufficient physical activity in the early years is mounting. This study aimed to determine the relationship between maternal and infant objectively measured physical activity, and to examine the diurnal interactions between these behaviours while accounting for potential covariates.

Methods: Mothers and infants ( $n=152$ pairs; infants aged 3-24 months) were recruited from Soweto, South Africa, and physical activity was measured using a wrist worn accelerometer (Axivity AX3, Axivity Ltd., Newcastle-uponTyne, UK) for 3-7 days. Mothers completed sleep diaries recording night time-in-bed (used as a proxy for nocturnal sleep status) for themselves and their infant; and reported times during which their infant was in their personal care (caregiver status) for each day during the measurement period. Significant correlates of infant physical activity, as well as the interactions between mother's physical activity, day of the week, sleep status, and caregiver status, were included in panel regression analyses with infant physical activity as the outcome.
\end{abstract}

Results: There was an equal distribution of boys and girls, and their age ranged from 2.6 to 24.5 months. The majority of mothers (73\%) did not spend any time apart from their infant. During weekdays, the combined effect of mother's physical activity ( $\beta=0.11)$, the interactions between mother's physical activity and caregiver status $(\beta=0.17)$, and sleep status ( $\beta=-0.04$ ) on infant physical activity was $\beta=0.24$; while during weekend days this association was $\beta=0.21$; and was largely moderated by the interaction between the mother being with the infant and her activity levels ( $\beta=0.23)$, but partly attenuated by mother's physical activity independent of other variables ( $\beta=-0.04)$. For each hour of the day, for both mother and infant, peaks of physical activity were higher when the mother was not the primary caregiver.

Conclusions: Infant physical activity levels were strongly associated with their mother's activity levels particularly during the week; this relationship was stronger when mothers were more active while looking after their infant. Mothers should be encouraged to be active when looking after their children, particularly during the week, and to provide infants with as much opportunity to be active as possible.

Keywords: Physical activity, Infant, Caregiving, Behaviour, Diurnal variation, Intensity distribution

\footnotetext{
* Correspondence: alessandra.prioreschi@wits.ac.za

${ }^{1}$ Department of Paediatrics, School of Clinical Medicine, Faculty of Health

Sciences, MRC/WITS Developmental Pathways for Health Research Unit,

University of Witwatersrand, Johannesburg, South Africa

Full list of author information is available at the end of the article
}

(c) The Author(s). 2018 Open Access This article is distributed under the terms of the Creative Commons Attribution 4.0 International License (http://creativecommons.org/licenses/by/4.0/), which permits unrestricted use, distribution, and reproduction in any medium, provided you give appropriate credit to the original author(s) and the source, provide a link to the Creative Commons license, and indicate if changes were made. The Creative Commons Public Domain Dedication waiver (http://creativecommons.org/publicdomain/zero/1.0/) applies to the data made available in this article, unless otherwise stated. 


\section{Background}

Evidence for the importance of accumulating sufficient physical activity in the early years is mounting. Physical activity in the first few years of life has been associated with motor and cognitive development [1], and with body composition $[1,2]$; and some tracking into later life has been shown $[3,4]$ therefore implying an association with metabolic risk in later life [5]. However, there is limited data available assessing physical activity in the first 2 years of life [6].

In the first 2 years of life, it is logical to assume that infant physical activity is largely dependent on their parents, and the opportunities that they provide their children to be active. Recommendations state that infants need to be provided with sufficient space to move and play, and that parents should provide a stimulating environment that encourages exploration and interaction, and that time spent restricted should be minimal thus allowing infants to move freely [7]. Movements in the first year of life often occur in sporadic, short-bursts [6], and should include a variety of activities such as arm and leg movements, tummy time (30 min per day is recommended) lifting of head, rolling, reaching, grasping, and eventually sitting and crawling. In the second year of life more defined movements such as walking and running, climbing and jumping start evolving; and recommendations advise $180 \mathrm{~min}$ of active time per day accumulated in a variety of ways and incorporating high energy activity $[8,9]$. These movements are important for setting up motor competencies and physical literacy in early life. As children get older and their behaviours become more autonomous, it is likely that they will be influenced by their parents' activity levels through role modeling, as well as through joint participation in physical activity $[10,11]$, and potentially even through a genetic predisposition to be more or less active [12, 13]. Indeed, studies have shown that physical activity levels tend to aggregate within families [14], particularly when considering very high and very low intensity activities [15-18]. Therefore, in order to improve infant physical activity, it seems justified to target their parents - who can be educated around the importance of providing opportunities for their infants to be active, can be provided with tools to increase their self-efficacy for effectively improving their infants' physical activity, and can be advised to increase their own activity levels in order to improve their own health, as well as that of their infant. Indeed, existing behavioural interventions use parents as agents of change to affect multiple infant behaviours [19-22].

However, the evidence for associations between parent and child objectively measured physical activity levels is conflicted [23], and very little data exists examining these relationships in the first 2 years of life. This is an important period of life for setting up growth, health and behavioural trajectories, including establishing healthy physical activity patterns $[4,24]$. There are various factors that have been shown to influence infant and young children's physical activity levels and may thus influence the relationship between parent and child physical activity. For example, infant's physical activity has been shown to be influenced by interaction with other children [25], developmental stage [26], and various maternal factors such as education, employment status and maternal activity behaviours [27-29]. Furthermore, diurnal variation in patterns of physical activity levels has been shown in toddlers [30,31]. Since many children in Soweto do not have a father present in the home throughout the day [32], we focus here on maternal-infant interactions. Therefore, the aims of this study were to determine the relationship between maternal and infant objectively measured physical activity, and to examine the diurnal interactions between these behaviours while accounting for potential covariates.

\section{Methods \\ Participants and procedures}

For the purpose of this observational study, all infants ( $<12$ months) and toddlers (12-24 months) will be referred to as infants. Mothers and their infants $(n=152$ pairs), who were already involved in a separate study at the Developmental Pathways for Health Research Unit (DPHRU) within the Chris Hani Baragwanath Academic Hospital, were contacted telephonically and invited to participate in this study. The recruitment strategy aimed to obtain a convenience sample with an equal spread of infants at various ages and developmental stages (i.e.: 3-, 6-, 12-, 18-, and 24-months). Exclusion criteria included any diagnosed developmental abnormalities that may impact on normal movement or development, as well as maternal inability to understand the questionnaires. Mothers were required to read and sign informed consent and assent documents for themselves and their infant, and were free to withdraw from the study at any time. Data collection took place at DPHRU in Soweto, South Africa. Soweto is a peri-urban setting, which is home to over 1.2 million inhabitants, accounting for one third of the population of Johannesburg (South Africa's largest city). Ethical approval for this study was provided by the University of the Witwatersrand Human Research Ethics Committee (M150632). At the first visit, all demographic information was collected, anthropometric measurements taken, and both mother and infant were fitted with an accelerometer to be worn on their non-dominant wrist (all infants wore the monitors on their left wrist). Mothers were also provided with sleepand caregiver diaries to complete. One week later, mothers were required to return the accelerometers and 
diaries. If participants were unable to return the devices, devices were collected from the participants' homes.

\section{Measures \\ Mother and infant physical activity}

Physical activity was measured using a wrist worn accelerometer (Axivity AX3, Axivity Ltd., Newcastle-upon-Tyne, UK), which has been used in large-scale adult population studies [33]. The accelerometer was worn in a standard silicon wrist-band by the mothers, and in a specially designed fabric band (Open Lab, Newcastle, UK) by the infants. The design and feasibility of this infant band has been described previously [34]; briefly the infant band was perceived to be safe, comfortable and acceptable according to mothers, and compliance wearing the band as well as technical reliability of the device data was very good (98\% provided at least 3 days of valid data).

Monitors were initialised to capture triaxial acceleration data at $100 \mathrm{~Hz}$ with a dynamic range of $+-8 \mathrm{~g}$. All participants were asked to wear the monitors at all times for a one-week period. Raw acceleration data was downloaded and auto-calibrated to local gravity using methods described elsewhere [35]. Vector magnitude was calculated as the root of sum of squared $x_{-}, y_{-}$, and $\mathrm{z}$-axis acceleration, following which a high- $(0.2 \mathrm{~Hz})$ and low- $(20 \mathrm{~Hz})$ pass frequency filter was applied to the data in order to remove gravity, as well as high-frequency noise [36]. The resulting variable provides an approximation of acceleration due to human movement alone (expressed in $\mathrm{mg}$ ). Physical activity was then summarised at 15-min level representing the average physical activity intensity for each time period [37]. Non-wear was identified based on the standard deviation of each axis being below $13 \mathrm{mg}$ for $>1 \mathrm{~h}$ [37]. Since data was reported and compared at the 15-min interval level, any interval where non-wear was detected was excluded, and only periods with complete 15 -min wear were included. Whole days were excluded if more than $40 \%$ of total accelerometer data for a given day was detected as non-wear. The accelerometer time-series data were annotated with maternal-reported night time-in-bed (nocturnal sleep status) for themselves and their infant, and with caregiver times according to the diaries (details below). Accelerometer time-series data were then coded with sleep status (yes/no) and caregiver status (yes/no).

\section{Anthropometry and demographics}

Mothers' height was measured to the nearest $1 \mathrm{~mm}$ using a wall-mounted stadiometer (Holtain, UK), and weight was measured to the nearest $0.1 \mathrm{~kg}$ using a digital scale (Dismed, USA). Mothers' body mass index (BMI) was calculated as (weight $\left.(\mathrm{kg}) / \mathrm{height}(\mathrm{m})^{2}\right)$ and categorised as underweight $\left(<18.5 \mathrm{~kg} / \mathrm{m}^{2}\right)$, normal weight $\left(\geq 18.5 \mathrm{~kg} / \mathrm{m}^{2}\right.$ and $\left.<25 \mathrm{~kg} / \mathrm{m}^{2}\right)$ or overweight/obese $\left(\geq 25.5 \mathrm{~kg} / \mathrm{m}^{2}\right)$. Infant length was measured to the nearest $1 \mathrm{~mm}$ using an infantometer (Chasmors Ltd., UK), and weight was measured to the nearest $0.1 \mathrm{~kg}$ using a digital scale (Dismed, USA). All anthropometry measurements were completed twice by trained research staff according to standardised procedures, and the average of the two values was used. Infant BMIs were converted to age-specific z scores according to the 2006/2007 World Health Organisation (WHO) growth standards [38] using the WHO Anthro software [39].

Mothers were asked to report their date of birth, and their infant's date of birth and gender. Mothers were also asked to report whether they had any other children, as well as details of their employment (whether or not they had a full-time job and how many hours they worked per day during the week and on weekends).

\section{Diaries}

During the measurement period ( 7 days), mothers were asked to complete sleep diaries recording the time at which their infant was put to bed for the night, and the time at which they were picked up from bed in the morning. Mothers were also asked to report their own time-to-bed and wake times. If sleep diary data was missing, values were imputed based on sample trends for days and times from the whole sample. These time-in-bed variables were thus considered as crude proxies for nocturnal sleep status for mothers and infants. Mothers were further asked to report times during which their infant was not in their personal care for each day during the measurement period in order to determine caregiver status, and to describe who looked after their infant while not in their own care. Three mothers had missing caregiver data - two of these mothers had reported not having a full-time job and being full-time mothers, and were therefore considered to be with their infant at all times. The third mother reported having a job, and her reported working hours were therefore considered time apart from her infant, while non-work hours were considered time with her infant.

\section{Developmental milestones}

According to maternal reported attainment of milestones, infants between 3 and 12 months were categorised as (1) not yet mobile (2) crawling or (3) walking. Between 12 and 18 months infants were categorised as (2) crawling or (3) walking, and at 24 months all infants were presumed to be walking [40].

\section{Statistical analysis}

All statistical analyses were conducted using STATA 13 for Mac. Participant characteristics were summarised 
and presented as mean (SD), n (\%), or median (IQR). Linear correlations were used to detect significant associations between infant and mother physical activity (mean vector magnitude, mg), and potential correlates thereof (infant gender, infant and maternal age, infant and maternal BMI, sleep status, caregiver status, duration apart, maternal employment and hours spent at her job, parity and number of siblings, and infant developmental stage). Significant correlates of infant physical activity $(p<0.05)$, as well as the interactions between mother's physical activity, day of the week, sleep status, and caregiver status, were then included in panel regression analyses with infant physical activity as the dependent outcome. All regressions were controlled for maternal age and BMI, duration apart from infant, infant age and gender, infant BMI z score, developmental stage, number of siblings, maternal employment, and hour of the day. Data were stratified by week/ weekend due to the significant independent effect of the week/weekend variable. Wilcoxon rank-sum tests were conducted to determine differences in infant physical activity levels according to whether mother and infant were together or not; these analyses were further stratified by age and gender. A $p<0.05$ was considered significant in all cases.

\section{Results}

Infant and mother characteristics are shown in Table 1. Two mother-infant pairs lost their devices, and a further three infants and four mothers lost their devices. One mother's data was lost due to incorrect initialisation. Therefore, 142 mother-infant pairs provided useable physical activity data and were included in the analysis. There was an equal distribution of boys and girls, and their age ranged from 2.6 and 24.5 months, with a roughly equal distribution by age category: $22 \%$ were $\leq$ 3 months, 22\% were between 3 and 6 months, 21\% were between 6 and 12 months, 14\% were between 12 and 18 months, and $21 \%$ were between 18 and 24 months. The majority of mothers (73\%) did not spend any time apart from their infant (i.e.: they were the primary caregiver at all times) during the 7-day study period, and $27 \%$ of mothers were employed full-time during the study period. For those who did spend time apart from their infant, the mean duration of time apart was 8.3(3.9) hours per day. When mothers were not with their infant, $63 \%$ of infants were looked after by a friend or family member, $13 \%$ were in crèche, and $24 \%$ were looked after by a nanny. Two thirds of infants (67\%) were not the first child, and the number of siblings (for those who were not single children) ranged from 1 to 5 (with a median of 1). For both mother and infant, physical activity was significantly higher on the weekend compared to during the week (Table $1, p<0.01$ for both mothers and infants).

Table 2 shows the results of the panel regression analyses between candidate exposures and infant physical activity $(n=142)$, stratified by week/weekend day. Mother's physical activity was associated with infant physical activity regardless of the time of day, but this relationship was only significant on weekdays. During weekdays, the combined effect of mother's physical activity $(\beta=0.11)$, the interactions between mother's physical activity and caregiver status $(\beta=0.17)$, and sleep status $(\beta=-0.04)$, on infant physical activity was $\beta=0.24$; while during weekend days this association was $\beta=0.21$. On weekend days, this effect was largely moderated by the interaction between the mother being with the infant and her activity levels $(\beta=0.23)$, but was partly attenuated by mother's physical activity independent of other variables $(\beta=-0.04)$.

The diurnal distribution of the infant and maternal physical activity, stratified by mother's caregiver status and week/weekend day, is presented in Fig. 1. By visual

Table 1 Participant characteristics

\begin{tabular}{|c|c|}
\hline & $\begin{array}{l}\text { Mean (SD) or Median } \\
\text { (IQR) or } n(\%)\end{array}$ \\
\hline \multicolumn{2}{|l|}{ Infant factors } \\
\hline Boys $(n, \%)$ & $75(53)$ \\
\hline Age (months) & $11.7(2.6-24.5)$ \\
\hline Infant BMI z-score & $0.26(1.67)$ \\
\hline \multicolumn{2}{|l|}{ Physical activity } \\
\hline Overall physical movement $(\mathrm{mg})^{\mathrm{a}}$ & $17(5-64)$ \\
\hline Physical movement on weekdays (mg) & $16(5-63)$ \\
\hline Physical movement on weekend days (mg) & $21(5-67)$ \\
\hline \multicolumn{2}{|l|}{ Developmental Stage } \\
\hline Not yet mobile $(n, \%)$ & $69(49)$ \\
\hline Crawling (n, \%) & $30(21)$ \\
\hline Walking (n, \%) & $43(30)$ \\
\hline \multicolumn{2}{|l|}{ Maternal factors } \\
\hline Maternal age (years) & $29(6)$ \\
\hline BMI $\left(\mathrm{kg} / \mathrm{m}^{2}\right)$ & $28.3(7.4)$ \\
\hline Underweight (n, \%) & $7(5)$ \\
\hline Normal Weight (n, \%) & $45(32)$ \\
\hline Overweight/Obese (n, \%) & $90(63)$ \\
\hline Infant is first child (n, \%) & $47(33)$ \\
\hline \multicolumn{2}{|l|}{ Physical activity } \\
\hline Overall physical movement (mg) & $33(6-78)$ \\
\hline Physical movement on weekdays (mg) & $31(5-77)$ \\
\hline Physical movement on weekend days (mg) & $37(6-79)$ \\
\hline
\end{tabular}

${ }^{a}$ Movement measures are median activity-related acceleration, summarised in 15-min intervals 
Table 2 Panel regression associations with infant physical activity and interactions

\begin{tabular}{|c|c|c|c|c|c|c|c|c|}
\hline \multirow[b]{3}{*}{ Mother's PA } & \multicolumn{4}{|l|}{ Weekday } & \multicolumn{4}{|c|}{ Weekend } \\
\hline & \multirow{2}{*}{$\begin{array}{l}\text { beta } \\
0.107\end{array}$} & \multicolumn{2}{|l|}{$95 \% \mathrm{Cl}$} & \multirow{2}{*}{$\begin{array}{l}P \text { value } \\
0.000\end{array}$} & \multirow{2}{*}{$\begin{array}{l}\text { beta } \\
-0.040\end{array}$} & \multicolumn{2}{|l|}{$95 \% \mathrm{Cl}$} & \multirow{2}{*}{$\begin{array}{l}P \text { value } \\
0.107\end{array}$} \\
\hline & & 0.072 & 0.143 & & & -0.088 & 0.009 & \\
\hline Infant age (months) & 0.627 & 0.313 & 0.942 & 0.000 & 0.936 & 0.626 & 1.246 & 0.000 \\
\hline Mother with infant (Yes) & -12.654 & -15.415 & -9.894 & 0.000 & -20.193 & -24.092 & -16.294 & 0.000 \\
\hline Interaction Mother PA X Mother with infant & 0.166 & 0.139 & 0.192 & 0.000 & 0.231 & 0.190 & 0.272 & 0.000 \\
\hline Infant in bed (No) & 20.287 & 18.862 & 21.712 & 0.000 & 20.026 & 18.083 & 21.968 & 0.000 \\
\hline Mother in bed (No) & 0.427 & -1.157 & 2.011 & 0.597 & -0.608 & -2.804 & 1.588 & 0.588 \\
\hline Interaction Mother's PA X Mother in bed & -0.037 & -0.062 & -0.013 & 0.003 & 0.024 & -0.004 & 0.053 & 0.094 \\
\hline
\end{tabular}

All regressions are controlled for hour of the day, mother's age, BMI, and duration apart from infant, maternal employment; and infant age, gender, BMI, developmental stage, and having a sibling

$P A$ physical activity, $B M I$ body mass index

interpretation it is evident that in all instances, peaks of physical activity were higher when the mother was not the primary caregiver (1203 person-hours of data considered) compared to when the mother was the primary caregiver (18,851 person-hours of data considered) for each given hour of the day. This held true for both mother and infant physical activity levels.

When stratifying infants by age (rounded to the nearest month), and week/weekend day, while considering only time-not-in-bed, infant physical activity during the week was significantly higher when the mother was not the primary caregiver at all ages except for at 18- and 24-months, at which ages infant PA was higher when the mother was the caregiver (Table 3). During the weekend, infant physical activity was significantly higher when the mother was the primary caregiver at 6-12and 24- months; but the opposite was true at 3- months. There was no difference in the overall relationship when stratifying by gender rather than age compared to the pooled sample; both boys and girls were significantly more active when their mother was not the primary caregiver on weekends as well as during weekdays. However, the strength of the differences between physical activity levels according to caregiver status was stronger in girls than boys $(p<0.01$ on both weekdays and weekend days for girls; and $p=0.002$ on weekends and $p=0.03$ on weekdays for boys).

\section{Discussion}

This is the first study that we are aware of to have examined the diurnal relationships between maternal and infant objectively measured physical activity, specifically taking into account whether the mother was with her infant or not during each time period. Infant physical activity was consistently and strongly associated with their mother's physical activity, yet this relationship was modified by whether the mother was the infant's primary caregiver at the time, and was different on weekdays compared to weekend days. For both mother and infant, physical activity was significantly higher on weekend days compared to weekdays. Furthermore, when taking into account the time of the day, age of the infant, and whether it was a weekday or weekend day, both mother and infant physical activity was higher during periods when the mother was not the primary caregiver.

It is important to note that the majority of mothers did not report spending any time apart from their infant during the study period, and so for the majority of time periods analysed the mother and infant were together. The higher levels of physical activity observed on weekend days compared to weekdays has been reported in older children [41], but is a novel finding in this young age group. Recently, a study conducted in older children (aged 5 years) and their mothers showed differences in the associations between co-participation in specific activities and the child's physical activity on weekdays compared to weekend days [42]; however mother and child moderate to vigorous physical activity was significantly correlated in both instances. The difference in direction of interactions observed between mother and infant physical activity on weekdays compared to weekend days in the current population is unique. On both weekdays and weekend days, the combined effect of mother's physical activity in conjunction with the interactions between sleep status and caregiver status on infant physical activity levels was approximately the same, and was largely due to the interaction between mother's physical activity and being the primary caregiver; yet on weekdays this effect was strengthened by the mother's physical activity main effect while on weekend days the effect was attenuated by mothers physical activity main effect. These relationships suggest that mother's habitual physical activity alone may not be as strongly associated with infant physical activity as is her physical activity when she is looking after her infant, particularly on the weekend. In other words, what the mother is doing while she is with her infant seems to be the factor most strongly associated with infant's physical activity levels. 

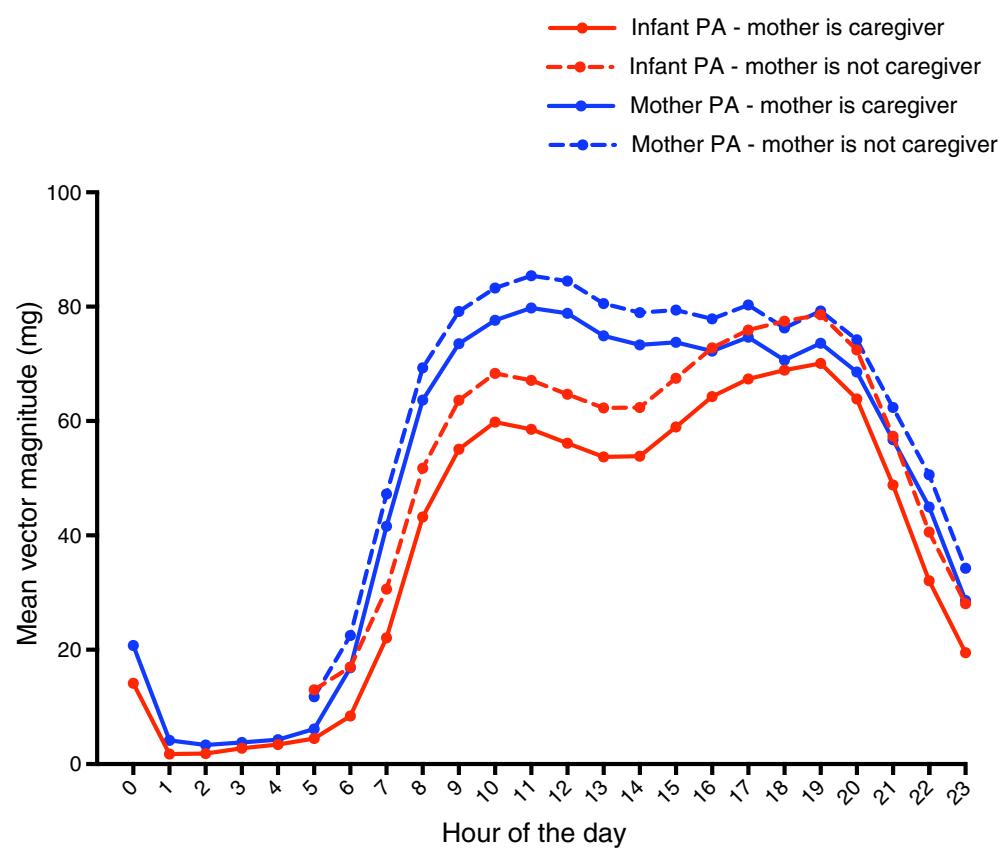

Fig. 1 Diurnal physical activity patterns for mother and infant when mother is the caregiver (solid lines) compared to when mother is not the caregiver (dotted lines). Infant activity is corrected for infant age and gender, and for the interaction between hour of day and day of week, and interaction between hour of day and caregiver status of the mother. Mother activity is corrected for the interaction between hour of day and day of week, and interaction between hour of day and caregiver status

It is thus possible that infant's behaviours may be dependent on interactions with-, and opportunities provided by their mothers or caregivers, particularly in the younger infants. It is, of course, possible that the direction of these associations are the opposite, such that more active infants stimulate mothers to be more active while taking care of them. However, regardless of the direction of this association, mothers (caregivers) would need to be the target for intervention, and should be encouraged to be more active (while with the infant or alone), as well as to provide infants with opportunities to be active. This is an important finding since it highlights a target area for intervention, particularly since the majority of mothers in this sample appeared to be with their infants at all times, increasing the potential for impacting infant behaviours. According to these findings, if mothers are encouraged to be more physically active while with their infant, this could lead to higher infant activity levels.

Also worth considering is the fact that both mother and infant physically activity levels were found to be higher at time periods when they were not together i.e. when the mother was not the caregiver. Somewhat similar to this although in an older age group, Jago et al. reported that in a sample of 10-11 year old children and their parents, while physical activity levels were similar between children and parents, it did not seem that activities were being done at the same time [17]. These findings potentially provide some insight into how mothers are interacting with their infants. Possibly, when mothers are not looking after their infants they are able to move about more freely, or choose to take this time alone to participate in physically active pursuits. Qualitative work done on mothers of infants in Midwestern United States

Table 3 Average infant physical activity stratified by age, maternal caregiver status, and week or weekend day. All values are mean (standard error of the mean, SEM)

\begin{tabular}{|c|c|c|c|c|c|c|}
\hline & \multicolumn{3}{|l|}{ Weekday } & \multicolumn{3}{|l|}{ Weekend } \\
\hline & Mother is caregiver & Mother is not caregiver & $\overline{p \text {-value }}$ & Mother is caregiver & Mother is not caregiver & $p$-value \\
\hline 3 -months $(n=31)$ & $40.4(0.5)$ & $47.2(2.0)$ & $<0.01$ & $41.9(0.6)$ & $34.4(2.3)$ & 0.02 \\
\hline 6 -months $(n=31)$ & $51.2(0.5)$ & $65.4(2.3)$ & $<0.01$ & $54.5(0.7)$ & $66.6(3.7)$ & $<0.01$ \\
\hline 12-months $(n=30)$ & $59.6(0.6)$ & $66.3(0.6)$ & $<0.01$ & $59.8(0.8)$ & $66.3(2.0)$ & $<0.01$ \\
\hline 18-months $(n=20)$ & $72.7(0.9)$ & $69.5(2.5)$ & $<0.01$ & $73.5(1.2)$ & $74.6(2.7)$ & 0.88 \\
\hline 24-months $(n=30)$ & $78.1(0.9)$ & $68.2(1.8)$ & $<0.01$ & $79.8(1.1)$ & $85.9(2.8)$ & 0.01 \\
\hline
\end{tabular}


has shown that mothers reported that they purposefully chose to engage in active behaviours when alone as a form of 'release', and very few engaged in active behaviours with their infant [43]. It is likely (and largely confirmed by the data collected on employment status in this sample) that for the majority of the time when mothers were not the primary caregiver of their infant, they were at work. Higher activity levels may therefore have been accumulated through active transport, which is still highly prevalent in South Africa [44], or through physically demanding jobs. Conversely, when mothers were looking after their infants they may have been spending this time in sedentary behaviours (such as watching TV, resting, sitting with their child while feeding). Sedentary behaviour participation is high in South African women, particularly in the age group within which these mothers fall [45], and so it is possible that these mothers were spending the majority of their time sedentary. Parent and child sedentary behaviours and TV viewing have been shown to be strongly correlated with each other, in some cases more so than correlations between higher intensity activities [16, 17].

In the present study, the behavioural interaction between the mother and infant that was occurring when they were together also seemed to be associated with the infant accumulating less activity. This could be attributed to co-participation in low intensity activities, likely in conjunction with mothers not providing access or opportunities for infants to be active, or due to some kind of learnt behaviour or role modeling - which may be more likely in the older age groups. In fact, when stratifying by age, older infants ( $>18$ months) were actually more active when their mother was looking after them during the week. Thus, it is possible that older infants have more autonomy and that their behaviours are less associated with their mother's activity levels, or that older infants are provided with more opportunities to be active (such as access to outdoor space) [46-48] regardless of what their mother is doing at the time. These considerations do not explain why infants are more active when their mother is not looking after them - presumably in these instances they are being looked after by another adult, and in Soweto this would often be another family member [49]. The reason for the mother's presence specifically influencing infant activity levels in an adverse manner is not clear. It is possible that non-maternal caregivers provide infants more opportunity to be active, by restraining them less and allowing them to move more freely. This may be due to the caregiver having multiple children to look after at a time, potentially having other chores to do around the home, and thus not spending as much time holding or carrying the infant. In Soweto, women often look after multiple children (biological and non-biological) in the home at a time [32]. Twenty of the mothers in the current study reported that their infant was in the care of another family member when not in their personal care, and family members consisted of grandmothers, aunts or siblings. Therefore it is likely that infants who were not with their mother were being looked after in the vicinity of other infants or children, thus increasing their likelihood to play alone or with these children [25]. In the current study having siblings was significantly associated with infant physical activity, and it is likely that infants could be with their siblings when not with their mother, thus increasing their activity levels. The same may be true for caregiving on weekends, during which time the mother may be with her infant but may not be the only caregiver, in which case her activity may be less related to her infant's activity. This provides a potential explanation for the attenuation of the relationship between mother and infant physical activity by mothers' physical activity on weekends only. Some children were reported to be attending a crèche or pre-school $(n=4)$ or looked after by a nanny $(n=8)$, which could possibly allow for a more stimulating environment with more opportunity to be active than they would receive at home with their mother.

It is unclear why this relationship is only significant on weekdays, and some context around the types of activities infants participate in on different days of the week would be useful. When stratifying by gender, while there were no significant differences between boys and girls, the effects of caregiver status on physical activity was much weaker for boys. Studies have shown that male children tend to receive more support for physical activity than females, and that this support is associated with higher physical activity levels [10]. It may be that mothers and other caregivers are providing male infants with more opportunities to be active, thereby attenuating differences that are dependent on mother caregiver status. It has also been shown that mothers may have more influence on their daughter's than their son's physical activity levels; while fathers may have more influence on their son's activity levels [10]. Since we did not measure father's activity levels, we cannot explore this possibility; however in Soweto many fathers do not live with their children and therefore may not play as strong a role as is seen in other contexts [32] - in fact only one mother in the present study reported that the father of the infant was a caregiver during the study period, although this may have been interpreted as the specific tasks of feeding and nappy changing, and not neccesarily being present. It is possible that this study is showing some support for previous findings that mothers are not as likely to influence their sons' physical activity levels as they are their daughters' physical activity levels. Interventions should thus consider how best to target male 
infants' activity levels, and should be aware that female infants may be more likely to be influenced by their mother's behaviour.

An obvious limitation to this study is the lack of contextual information, which limits our understanding of the types of activities being done when mother and infant are together or apart, where these activities are being done, and who was interacting with the infant when they were not with their mother. Furthermore, it is possible that even when the mother was the primary caregiver, she was not directly interacting with her infant, thus complicating the interpretation of the correlation between mother and infant behaviours. In addition, the lack of contextual information means that we were unable to differentiate between infant accelerometer readings that were generated by self-initiated infant movements, compared to those which were generated by the mother or another caregiver moving the infant (i.e.: picking the infant up, rocking, changing etc). This is a limitation for any study attempting to objectively assess infant physical activity levels using accelerometers when movements are not always self-initiated, and further work is required in order to address this issue. A further methodological issue was the lack of information obtained on sleeping/ napping during the day, which limits the interpretation of the results, particularly for younger infants. Some of these findings may also be context specific, and therefore cannot necessarily be extrapolated to a population of infants outside of a similar low-middle-income setting. We also did not obtain information on the mother's level of education, which may have impacted on her interpretation of some of the questions. Lastly, due to the cross-sectional nature of the study, firm conclusions on causality cannot be drawn, and longitudinal studies and trials are required to further elucidate these relationships.

\section{Conclusions}

In conclusion, this study has shown that infant physical activity levels were strongly associated with their mother's activity levels particularly during the week, yet this relationship was stronger when mothers were being active while looking after their infant. Furthermore, both mother and infant were less active when together than when apart, and were less active on weekdays than on weekend days. These findings highlight potential targets for interventions aimed at increasing infant physical activity levels. Specifically, mothers should be encouraged to be active as much as possible when looking after their children, and to attempt to increase these levels during the week. In all instances, infants should be provided with as much opportunity to be active as possible.

\section{Abbreviations}

BMl: Body mass index; WHO: World Health Organization

\section{Acknowledgements}

We would like to acknowledge Antonia Smith and Thomas White (MRC Epidemiology Unit, UK) for assistance with the processing of the data, and Lutricia Moagi (MRCMits Developmental Pathways for Health Research Unit, SA) for her assistance with data collection.

\section{Funding}

The support of the DST-NRF Centre of Excellence in Human Development at the University of the Witwatersrand, Johannesburg in the Republic of South Africa is hereby acknowledged by AP. Opinions expressed and conclusions arrived at, are those of the author and are not to be attributed to the CoE in Human Development. The work of AP was also supported by the Claude Leon Foundation. The work of SB and KW was supported by UK Medical Research Council (MC_UU_12015/3) and the NIHR Biomedical Research Centre Cambridge (IS-BRC-1215-20014). LKM would like to acknowledge funding from the Academy of Medical Sciences-Newton Advanced Fellowship. None of the funders were involved in the design of the study, collection or analysis or interpretation of the data, or in writing of the manuscript.

\section{Availability of data and materials}

The datasets used and/or analysed during the current study are available from the corresponding author on reasonable request

\section{Authors' contributions}

AP was involved in conceptualisation of the manuscript, data collection, cleaning and analysis, and writing of the manuscript. SB and KW were involved in conceptualisation of the manuscript, processing of the data and edited the manuscript. SB was involved in analysis of the data. LKM conceptualised the project and edited the manuscript. All authors read and approved the final manuscript.

\section{Ethics approval and consent to participate}

Ethical approval was obtained from the Human Research Ethics Committee of the University of the Witwatersrand (ethics number M150632). All participants gave written and informed consent for participation in this study

Consent for publication

Not applicable.

\section{Competing interests}

The authors declare that they have no competing interests.

\section{Publisher's Note}

Springer Nature remains neutral with regard to jurisdictional claims in published maps and institutional affiliations.

\section{Author details}

${ }^{1}$ Department of Paediatrics, School of Clinical Medicine, Faculty of Health Sciences, MRC/WITS Developmental Pathways for Health Research Unit, University of Witwatersrand, Johannesburg, South Africa. ${ }^{2} \mathrm{MRC}$ Epidemiology Unit, University of Cambridge, Cambridge, UK.

Received: 30 November 2017 Accepted: 14 June 2018

Published online: 25 June 2018

\section{References}

1. Timmons BW, Leblanc AG, Carson V, Connor Gorber S, Dillman C, Janssen I, et al. Systematic review of physical activity and health in the early years (aged 0-4 years). Appl Physiol Nutr Metab. 2012;37(4):773-92. https://doi. org/10.1139/h2012-070. PubMed PMID: 22765840

2. Collings PJ, Brage S, Ridgway CL, Harvey NC, Godfrey KM, Inskip HM, et al. Physical activity intensity, sedentary time, and body composition in preschoolers. Am J Clin Nutr. 2013;97(5):1020-8. https://doi.org/10.3945/ajcn. 112.045088. PubMed PMID. 23553158; PubMed Central PMCID. PMCPMC3785144 
3. Friedman HS, Martin LR, Tucker JS, Criqui MH, Kern ML, Reynolds CA. Stability of physical activity across the lifespan. J Health Psychol. 2008;13(8):1092-104. https:/doi.org/10.1177/1359105308095963. PubMed PMID: 18987082

4. Jones RA, Hinkley T, Okely AD, Salmon J. Tracking physical activity and sedentary behavior in childhood: a systematic review. Am J Prev Med. 2013; 44(6):651-8. https://doi.org/10.1016/j.amepre.2013.03.001. PubMed PMID: 23683983

5. Wadhwa PD, Buss C, Entringer S, Swanson JM. Developmental origins of health and disease: brief history of the approach and current focus on epigenetic mechanisms. Semin Reprod Med. 2009;27(5):358-68. https://doi org/10.1055/s-0029-1237424. PubMed PMID: 19711246; PubMed Central PMCID: PMCPMC2862635

6. Prioreschi A, Micklesfield LK. A scoping review examining physical activity measurement and levels in the first 2 years of life. Child Care Health Dev. 2016;42(6):775-83. https://doi.org/10.1111/cch.12382. PubMed PMID: 27491934

7. Tremblay MS, Leblanc AG, Carson V, Choquette L, Connor Gorber S, Dillman $C$, et al. Canadian physical activity guidelines for the early years (aged $0-4$ years). Appl Physiol Nutr and Med. 2012;37(2):345-56.

8. Tremblay M, Chaput J, Adamo K, Aubert S, et al. Canadian 24-hour movement guidelines for the early years ( $0-4$ years): an integration of physical activity, sedentary behaviour, and sleep. BMC Public Health. 2017; 17(Suppl 5):874. https://doi.org/10.1186/s12889-017-4859-6.

9. Okely AD, Ghersi D, Hesketh KD, Santos R, Loughran SP, Cliff DP, et al. A collaborative approach to adopting/adapting guidelines - the Australian 24hour movement guidelines for the early years (birth to 5 years): an integration of physical activity, sedentary behavior, and sleep. BMC Public Health. 2017;17(Suppl 5):869. https://doi.org/10.1186/s12889-017-4867-6. Epub 2017/12/09. PubMed PMID: 29219094; PubMed Central PMCID: PMCPMC5773882

10. Gustafson S, Rhodes R. Parental correlates of physical activity in children and early adolescents. Sports Med. 2006:36:79-97.

11. Edwardson C, Gorely T. Parental influences on different types and intensities of physical activity in youth: a systematic review. Psychol Sport Exerc. 2010; 11:522-35. https://doi.org/10.1016/j.psychsport.2010.05.001.

12. Pérusse L, Tremblay A, Leblanc C, B C. Genetic and environmental influences on level of habitual physical activity and exercise participation. Am J Epidemiol. 1989;129:1012-22.

13. Lauderdale DS, Fabsitz R, Meyer JM, Sholinsky P, Ramakrishnan V, Goldberg J. Familial determinants of moderate and intense physical activity: a twin study. Med Sci Sport Exerc. 1997;29:1062-8.

14. Freedson PS, Evenson S. Familial aggregation in physical activity. Res Q Exerc Sport. 1992:63:453.

15. Anderssen N, Wold B, Torsheim T. Are parental health habits transmitted to their children? An eight year longitudinal study of physical activity in adolescents and their parents. J Adolesc. 2006;29:513-24. https://doi.org/10. 1016/j.adolescence.2005.05.011.

16. Fogelholm M, Nuutinen O, Pasanen M, Myohanen E, Säätelä T. Parent-child relationship of physical activity patterns and obesity. Int J Obes. 1999;23: 1262-8.

17. Jago R, Fox KR, Page AS, Brockman R, Thompson JL. Parent and child physical activity and sedentary time: do active parents foster active children? BMC Public Health. 2010;10:194. https://doi.org/10.1186/14712458-10-194. PubMed PMID: 20398306; PubMed Central PMCID: PMCPMC2868817

18. Edwardson $\mathrm{CL}$, Gorely T. Parental influences on different types and intensities of physical activity in youth: a systematic review. Psychol Sport Exerc. 2010;11:522-35. https://doi.org/10.1016/j.psychsport.2010.05.001.

19. Taylor BJ, Heath AL, Galland BC, Gray AR, Lawrence JA, Sayers RM, et al. Prevention of overweight in infancy (POI.Nz) study: a randomised controlled trial of sleep, food and activity interventions for preventing overweight from birth. BMC Public Health. 2011;11:942. https://doi.org/10.1186/14712458-11-942. PubMed PMID: 22182309; PubMed Central PMCID: PMCPMC3293097

20. Campbell K, Hesketh K, Crawford D, Salmon J, Ball K, McCallum Z. The infant feeding activity and nutrition trial (INFANT) an early intervention to prevent childhood obesity: cluster-randomised controlled trial. BMC Public Health. 2008:8:103. https://doi.org/10.1186/1471-2458-8-103. PubMed PMID: 18373877; PubMed Central PMCID: PMCPMC2346474

21. Paul IM, Williams JS, Anzman-Frasca S, Beiler JS, Makova KD, Marini ME, et al. The intervention nurses start infants growing on healthy trajectories
(INSIGHT) study. BMC Pediatr. 2014;14:184. https://doi.org/10.1186/14712431-14-184. PubMed PMID: 25037579; PubMed Central PMCID: PMCPMC4105401

22. Wen LM, Rissel C, Baur LA, Hayes AJ, Xu H, Whelan A, et al. A 3-arm randomised controlled trial of communicating healthy beginnings advice by telephone (CHAT) to mothers with infants to prevent childhood obesity. BMC Public Health. 2017;17(1):79. https://doi.org/10.1186/s12889-016-4005-x. PubMed PMID: 28088203; PubMed Central PMCID: PMCPMC5237545

23. Fuemmeler B, Anderson C, Mâsse L. Parent-child relationship of directly measured physical activity. Int J Behav Nutr Phys Act. 2011;8:17.

24. Barker D. Developmental origins of health and disease. J Epidemiol Commun Health. 2004;58:114-5.

25. Hnatiuk J, Salmon J, Campbell KJ, Ridgers ND, Hesketh KD. Early childhood predictors of toddlers' physical activity: longitudinal findings from the Melbourne InFANT program. Int J Behav Nutr Phys Act. 2013;10:123. https:// doi.org/10.1186/1479-5868-10-123. PubMed PMID: 24188589; PubMed Central PMCID: PMCPMC4228319

26. Ridgway $\mathrm{CL}$, Ong KK, Tammelin TH, Sharp S, Ekelund U, Jarvelin MR. Infant motor development predicts sports participation at age 14 years: northern Finland birth cohort of 1966. PLoS One. 2009;4(8):e6837. https://doi.org/10. 1371/journal.pone.0006837. PubMed PMID: 19718258; PubMed Central PMCID: PMCPMC2729394

27. Duch $H$, Fisher EM, Ensari I, Harrington A. Screen time use in children under 3 years old: a systematic review of correlates. Int J Behav Nutr Phys Act. 2013;10:102. https://doi.org/10.1186/1479-5868-10-102. PubMed PMID: 23967799; PubMed Central PMCID: PMCPMC3844496

28. Certain LK, Kahn RS. Prevalence, correlates and trajectory of television viewing among infants and toddlers. Paediatrics. 2002;109(4):634-42.

29. Hager ER, Gormley CE, Latta LW, Treuth MS, Caulfield LE, Black MM. Toddler physical activity study: laboratory and community studies to evaluate accelerometer validity and correlates. BMC Public Health. 2016;16:936. https://doi.org/10.1186/s12889-016-3569-9. PubMed PMID: 27600404; PubMed Central PMCID: PMCPMC5011903

30. Berglind D, Tynelius P. Objectively measured physical activity patterns, sedentary time and parent-reported screen-time across the day in four-yearold Swedish children. BMC Public Health. 2017;18(1):69. https://doi.org/10. 1186/s12889-017-4600-5. PubMed PMID: 28764730; PubMed Central PMCID: PMCPMC5540346

31. Faurholt-Jepsen D, Hansen KB, van Hees VT, Christensen LB, Girma T, Friis H, et al. Children treated for severe acute malnutrition experience a rapid increase in physical activity a few days after admission. J Pediatr. 2014; 164(6):1421-4. https://doi.org/10.1016/j.jpeds.2014.02.014. PubMed PMID: 24657125

32. Jordan N, Patel L, Hochfeld T. Early motherhood in Soweto: the nexus between the child support grant and developmental social work services. Soc Work. 2014;50(3):392-409. https://doi.org/10.15270/50-2-406.

33. Doherty A, Jackson D, Hammerla N, Plotz T, Olivier P, Granat MH, et al. Large scale population assessment of physical activity using wrist worn accelerometers: the UK biobank study. PLoS One. 2017;12(2):e0169649. https://doi.org/10.1371/journal.pone.0169649. PubMed PMID: 28146576; PubMed Central PMCID: PMCPMC5287488 study. PO has previously been a director of Axivity Ltd. NH has previously consulted for Axivity Ltd. The partners of DJ and PO own shares in Axivity. This does not alter our adherence to PLOS ONE policies on sharing data and materials

34. Prioreschi A, Nappey T, Westgate K, Olivier P, Brage S, Micklesfield LK. Development and feasibility of a wearable infant wrist band for the objective measurement of physical activity using accelerometery. Pilot Feasibility Stud. 2018;4:60. https://doi.org/10.1186/s40814-018-0256-x. Epub 2018/03/07. PubMed PMID: 29507750; PubMed Central PMCID: PMCPMC5831201

35. van Hees VT, Fang Z, Langford J, Assah F, Mohammad A, da Silva IC, et al. Autocalibration of accelerometer data for free-living physical activity assessment using local gravity and temperature: an evaluation on four continents. J Appl Physiol (1985). 2014;117(7):738-44. https://doi.org/10. 1152/japplphysiol.00421.2014. PubMed PMID: 25103964; PubMed Central PMCID: PMCPMC4187052

36. van Hees VT, Gorzelniak L, Dean Leon EC, Eder M, Pias M, Taherian S, et al. Separating movement and gravity components in an acceleration signal and implications for the assessment of human daily physical activity. PLoS One. 2013;8(4):e61691. https://doi.org/10.1371/journal.pone.0061691. PubMed PMID: 23626718; PubMed Central PMCID: PMCPMC3634007 
37. White T, Westgate K, Wareham NJ, Brage S. Estimation of physical activity energy expenditure during free-living from wrist Accelerometry in UK adults. PLoS One. 2016;11(12):e0167472. https://doi.org/10.1371/journal. pone.0167472. PubMed PMID: 27936024; PubMed Central PMCID: PMCPMC5147924

38. de Onis M. WHO child growth standards based on length/height, weight and age. Acta Paediatr. 2006;95:76-85.

39. WHO. Anthro for personal computers, version 3.2.2, 2011: Software for assessing growth and development of the world's children. Geneva: WHO; 2010. http://www.who.int/childgrowth/software/en/.

40. WHO Multicentre growth reference study group. WHO motor development study: windows of achievement for six gross motor development milestones. Acta Paediatr. 2006;450:86-95. https://doi.org/10.1080/ 08035320500495563.

41. Fairclough SJ, Boddy LM, Mackintosh KA, Valencia-Peris A, Ramirez-Rico E. Weekday and weekend sedentary time and physical activity in differentially active children. J Sci Med Sport. 2015;18(4):444-9. https://doi.org/10.1016/j. jsams.2014.06.005. PubMed PMID: 25011925

42. Hnatiuk JA, DeDecker E, Hesketh KD, Cardon G. Maternal-child coparticipation in physical activity-related behaviours: prevalence and crosssectional associations with mothers and children's objectively assessed physical activity levels. BMC Public Health. 2017;17(1):506. https://doi.org/10. 1186/s12889-017-4418-1. PubMed PMID: 28545418; PubMed Central PMCID: PMCPMC5445458

43. Dinkel D, Snyder K, Kyvelidou A, Molfese V. He's just content to sit: a qualitative study of mothers' perceptions of infant obesity and physical activity. BMC Public Health. 2017;17(1):585. https://doi.org/10.1186/s12889017-4503-5. PubMed PMID: 28629410; PubMed Central PMCID: PMCPMC5477242

44. Micklesfield LK, Munthali RJ, Prioreschi A, Said-Mohamed R, van Heerden A, Tollman S, et al. Understanding the relationship between socio-economic status, physical activity and sedentary behaviour, and adiposity in young adult south African women using structural equation modelling. Int J Environ Res Public Health. 2017;14(10) https://doi.org/10.3390/ ijerph14101271. PubMed PMID: 29065528

45. Shisana O, Labadarios D, Rehle T, Simbayi L, Zuma K, Dhansay A, et al. South African National Health and Nutrition Examination Survey (SANHANES-1): 2014 Edition. Cape Town: HSRC Press; 2014.

46. Hinkley T, Crawford D, Salmon J, Okely AD, Hesketh K. Preschool children and physical activity: a review of correlates. Am J Prev Med. 2008;34(5):43541. https://doi.org/10.1016/j.amepre.2008.02.001. PubMed PMID: 18407012

47. Hesketh KR, O'Malley C, Paes VM, Moore H, Summerbell C, Ong KK, et al. Determinants of change in physical activity in children 0-6 years of age: a systematic review of quantitative literature. Sports Med. 2017;47(7):1349-74. https://doi.org/10.1007/s40279-016-0656-0. PubMed PMID: 27988875; PubMed Central PMCID: PMCPMC5488114

48. Hesketh KD, Crawford DA, Abbott G, Campbell K, Salmon J. Prevalence and stability of active play, restricted movement and television viewing in infants. Early Child Dev Care. 2014;185(6):883-94. https://doi.org/10.1080/ 03004430.2014.963066.

49. Evans J. Child-rearing practices in sub-Saharan Africa: an introduction to the studies. Washington: The World Bank; 1994.

\section{Ready to submit your research? Choose BMC and benefit from:}

- fast, convenient online submission

- thorough peer review by experienced researchers in your field

- rapid publication on acceptance

- support for research data, including large and complex data types

- gold Open Access which fosters wider collaboration and increased citations - maximum visibility for your research: over $100 \mathrm{M}$ website views per year

At BMC, research is always in progress.

Learn more biomedcentral.com/submissions 